\title{
KOMPETISI ALAT PENANGKAPAN IKAN SKALA KECIL DI PELABUHAN PERIKANAN PANTAI TEGALSARI
}

\author{
Small Scale Fishing Gear Competition in Tegalsari Fishing Port \\ Oleh: \\ Lukman Hakim ${ }^{1}$, Eko Sri Wiyono ${ }^{2}$ Ronny Irawan Wahju ${ }^{2}$ \\ ${ }_{1}$ Program Studi Pemanfaatan Sumberdaya Perikanan, FPIK, IPB; lukmanhakim2525@gmail.com \\ 2 FPIK, IPB; eko_ipb@yahoo.com; rwahyu06@gmail.com
}

Diterima: 22 September 2017; Disetujui: 16 Mei 2018

\begin{abstract}
The fishermen in Tegalsari Fishing Port have been using vary of fishing gears that is feared could competing in getting catches. This research aims to identify fishing gear types according to fishing gear vessel's volume, fishing time and frequency in every operation, fishing gears productivity, and fishing gears competition. The subject of this research are four biggest number of fishing gear units in PPP Tegalsari (cantrang, arad, gillnet, and mini purse seine) with fishing vessel volume below 10 GT. Samples were taken with purposive sampling method and collected through filling out the questionnaires. The fishing gears's productivity determined by the number of catch per unit effort (CPUE). Furthermore, the fishing gear competition mapped by classified the matrix of transformed fishing gear's productivity number into some clusters with hierarchycal cluster analysis (HCA). The results show the dominant fishing gear that local fishermen use are cantrang $(5,6,10 \mathrm{GT})$, arad $(3,5,6,10 \mathrm{GT})$, gillnet (6 GT), and mini purse seine (9 GT), the highest average of fishing gear operation time is gillnet (3 hours), and the least is mini purse seine ( \pm 1 hour) and the highest average of fishing setting number is cantrang by 27 times/trip and mini purse seine is the least by 5 times/trip, the highest productivity gained by cantrang (5163 kg/trip) and the least is Gillnet (363 kg/trip), and the most intensive fishing gear competition is between cantrang (5 and 6 GT), arad (3.5, and $6 \mathrm{GT}$ ), and gillnet (3 GT).
\end{abstract}

Keywords: Competition, fishing gear, productivity

\section{ABSTRAK}

Nelayan di Pelabuhan Perikanan Pantai Tegalsari menggunakan alat tangkap yang beragam. Dikhawatirkan antar alat tangkap saling berkompetisi dalam mendapatkan hasil tangkapan ikan. Penelitian ini bertujuan untuk mengidentifikasi jenis alat tangkap berdasarkan GT kapal, waktu untuk 1 kali operasi dan frekuensinya dalam satu trip penangkapan ikan, produktivitas alat tangkap, dan kompetisi antar alat tangkap. Alat tangkap yang diamati adalah cantrang, arad, gillnet dan mini purse seine yang dioperasikan menggunakan kapal berukuran $\leq 10$ GT. Pengumpulan data dilakukan melalui penyebaran kuesioner. Produktivitas alat tangkap ditentukan berdasarkan nilai CPUE dan kompetisi antar alat tangkap ditentukan menggunakan metode hierachycal cluster analysis. Hasil penelitian menunjukkan: jenis alat tangkap berdasarkan GT kapal yakni cantrang (5, 6 dan $10 \mathrm{GT})$, arad (3, 5, 6 dan $10 \mathrm{GT})$, gillnet (6 GT), dan mini purse seine (9 GT); waktu untuk 1 kali operasi penangkapan ikan tertinggi pada alat tangkap gillnet ( 3 jam) dan terendah pada cantrang dan mini purse seine ( \pm 1 jam) serta jumlah operasi penangkapan ikan per trip tertinggi pada alat tangkap cantrang (27 kali/trip) dan terendah pada mini purse seine (5 kali/trip); produktivitas tertinggi pada alat tangkap cantrang (5163 kg/trip) dan 
terendah pada gillnet (363 kg/trip); dan antar alat tangkap yang berkompetisi secara ketat adalah cantrang ( 5 dan $6 \mathrm{GT})$, arad (3, 5 dan $6 \mathrm{GT}$ ), dan gillnet 6 GT.

Kata kunci: Kompetisi, alat penangkapan ikan, produktivitas.

\section{PENDAHULUAN}

Sumber daya ikan merupakan sumber daya hayati yang bersifat dapat diperbaharui (renewable) dan open access yang setiap orang berhak dan bebas memanfaatkan sumber daya tersebut secara bersama-sama (common property resources) (Junus 2012). Kegiatan penangkapan ikan perlu dilakukan secara hati-hati untuk menjaga keberlanjutannya agar sumber daya ikan dapat dinikmati oleh generasi mendatang tanpa dibatasi waktu. Hal yang dapat mengancam kelestarian ketersediaan sumber daya ikan adalah kegiatan penangkapan ikan yang sangat intensif (Susanto et al. 2015).

Kegiatan penangkapan ikan ditujukan untuk mendapatkan hasil tangkapan sesuai dengan yang ditargetkan. Ada beberapa faktor yang mempengaruhi perolehan hasil tangkapan, diantaranya adalah jenis alat tangkap yang digunakan, ukuran kapal, dan cara pengoperasian alat tangkap; dalam hal ini adalah waktu yang dibutuhkan untuk satu kali operasi penangkapan ikan dan jumlah operasi penangkapan ikan per trip.

Kegiatan penangkapan ikan dapat dilakukan menggunakan kapal dengan ukuran (gross tonnase) yang berbeda-beda. Makin besar ukuran kapal (GT), maka armada penangkapan ikan dapat melakukan kegiatan penangkapan dalam waktu yang lebih lama dengan asumsi perbekalan selama melaut mencukupi. Jenis alat tangkap yang digunakan oleh masingmasing armada penangkapan ikan dapat sama atau berbeda.

Kegiatan penangkapan ikan yang dilakukan secara intensif menggunakan kapal yang beragam ukurannya dan beragam jenis alat tangkapnya terjadi di Pelabuhan Perikanan Pantai (PPP) Tegalsari. Diduga antar alat tangkap yang digunakan nelayan telah terjadi kompetisi dalam mendapatkan hasil tangkapan.

Dua alat penangkapan ikan atau lebih dapat saling berkompetisi (berinteraksi) ketika alat penangkapan tersebut mendapatkan jenis ikan yang sama dengan bobot yang hampir sama. Hal ini dapat mengarah pada terjadinya eksploitasi terhadap sumber daya ikan tersebut (Pan 2015). Atmaja dan Sadhotomo (2012) menyatakan bahwa eksploitasi bersama terhadap sumber daya milik bersama yang tidak dikelola dengan baik, dikhawatirkan dapat mengancam kelestarian ketersediaan stok ikan dan mengancam keberlanjutan kegiatan penangkapan ikan.

Sejauh ini, kajian tentang kompetisi antar alat penangkapan ikan masih belum banyak mendapatkan perhatian. Informasi ini sangat penting untuk dijadikan acuan dalam melakukan pengelolaan penggunaan alat tangkap secara proporsional.

Tujuan penelitian ini adalah untuk menganalisis: 1) jenis alat tangkap berdasarkan GT kapal yang digunakan nelayan PPP Tegalsari saat operasi penangkapan ikan, 2) waktu yang dibutuhkan untuk satu kali operasi penangkapan ikan, 3) jumlah operasi penangkapan ikan per trip, 4) produktivitas alat tangkap, dan 5) kompetisi antar alat tangkap berdasarkan nilai ketidaksamaan matrik produktivitas.

\section{METODE}

Penelitian ini dilakukan di Pelabuhan Perikanan Pantai (PPP) Tegalsari, Kota Tegal, Provinsi Jawa Tengah dari bulan Juli sampai Agustus tahun 2016. Penelitian ini dibatasi hanya pada empat jenis alat tangkap yang dominan digunakan nelayan PPP Tegalsari, yakni cantrang, arad, gillnet, dan mini purse seine yang dioperasikan dengan menggunakan kapal berukuran $\leq 10$ GT (skala kecil). Data yang digunakan dalam penelitian ini berupa data primer yang diperoleh melalui penyebaran kuesioner. Data primer yang dimaksud meliputi data hasil wawancara mengenai ukuran (GT) kapal, lama operasi penangkapan ikan, lama setting alat penangkapan ikan, jumlah operasi penangkapan ikan dalam satu trip, dan produktivitas hasil tangkapan.

Sampel ditentukan dengan metode purposive sampling, yaitu pengambilan sampel dilakukan secara sengaja sesuai dengan persyaratan yang didasarkan pada kriteria tertentu agar informasi yang diperoleh representatif. Kriteria nelayan yang dijadikan sampel adalah nelayan yang memiliki pengalaman melaut minimal dua puluh tahun, berpengalaman dalam mengoperasikan alat tangkap yang sama minimal sepuluh tahun berturut-turut dan berpengalaman mengelola hasil tangkapan dari alat tangkap yang sama minimal dua tahun. Berdasarkan kriteria tersebut, ada 152 nelayan cantrang, 278 nelayan arad, 27 nelayan gillnet, dan 61 nelayan mini purse seine. Jumlah nelayan 
yang menjadi sampel dari masing-masing jenis alat tangkap adalah $10 \%$ dari jumlah tersebut sehingga sampel dalam penelitian ini terdiri dari 15 nelayan cantrang, 28 nelayan arad, 3 nelayan gillnet, dan 6 nelayan mini purse seine.

Produktivitas alat tangkap ditentukan berdasarkan nilai Catch Per Unit Effort (CPUE) yang dihitung berdasarkan jumlah trip menggunakan rumus Gulland (1983) seperti yang diacu oleh Wurlianty et al. (2015), yakni:

$q=\frac{h}{f}$

dengan:

$\mathrm{q}=\mathrm{CPUE}$ (kg/trip)

$\mathrm{h}=$ Catch atau hasil tangkapan $(\mathrm{kg})$

$\mathrm{f}=$ Effort (trip)

Kompetisi antar alat tangkap ditentukan berdasarkan metode hierachycal cluster analysis. Data produktivitas berupa jenis ikan dan bobotnya yang diperoleh oleh suatu alat tangkap tertentu diolah lebih lanjut menggunakan rumus Squared Euclidean Distance, seperti yang dilakukan Yulianto dan Hidayatullah (2014). Pada penelitian ini, rumus yang digunakan Yulianto dan Hidayatullah (2014) dimodifikasi menjadi:

$d E\left(X_{i}, Y_{i}\right)=\sum_{i=1}^{n}\left(X_{i}-Y_{i}\right)$

dengan:

$X i=$ Nilai produktivitas komoditas ikan ke-i pada alat tangkap $X$

$Y i=$ Nilai produktivitas komoditas ikan ke-i pada alat tangkap $Y$

Data produktivitas hasil tangkapan diolah dengan cara mengubah suatu nilai ke bentuk matriks yang menjelaskan jarak antara suatu titik ke titik lain. Hasil perhitungan ini dapat menjelaskan bahwa lebar jarak menunjukkan perbedaan antar alat tangkap terhadap suatu komoditas tertentu. Semakin pendek jaraknya, maka kemiripan komoditas hasil tangkapan antar alat tangkap menjadi semakin tinggi, atau intensitas kompetisi semakin intensif.

\section{HASIL DAN PEMBAHASAN}

\section{Jenis Alat Tangkap Berdasarkan GT Kapal}

Alat tangkap cantrang dan arad merupakan alat tangkap yang paling banyak digunakan nelayan di Perairan Utara Jawa (Mahardhika 2008). Selain kedua alat tangkap tersebut, nelayan PPP Tegalsari juga mengoperasikan alat tangkap lainnya, dua diantaranya adalah gillnet dan mini purse seine. Alat tangkap ini dioperasikan oleh nelayan PPP Tegalsari menggunakan kapal dalam berbagai ukuran (GT).
Ukuran kapal merupakan volume bangunan kapal di atas maupun di bawah dek (Setianto 2007). Pada penelitian ini, ukuran (GT) kapal dilihat dari tanda selar kapal yang tertera pada surat pengukuran kapal. Tabel 1 adalah hasil penelitian tentang jenis alat tangkap yang digunakan nelayan PPP Tegalsari berdasarkan ukuran kapalnya.

Tabel 1 menunjukkan bahwa nelayan PPP Tegalsari mengoperasikan alat tangkap arad menggunakan kapal dengan ukuran paling beragam, yaitu 3, 5, 6, dan 10 GT. Alat tangkap ini juga dioperasikan oleh nelayan dari pesisir utara Kota Cirebon dan Batang menggunakan kapal berukuran < 10 GT (Khaerudin 2006; Sulistyowati 2017). Demikian halnya dengan cantrang dioperasikan oleh nelayan PPP Tegalsari menggunakan kapal dengan ukuran beragam yakni 5, 6, dan 10 GT (Tabel 1). Sejalan dengan hal ini, hasil penelitian Atmaja dan Nugroho (2012) mendapatkan cantrang juga dioperasikan oleh nelayan dari Batang, Juwana dan Rembang dengan menggunakan kapal berukuran $<10$ GT.

Di lain pihak, gillnet dioperasikan oleh nelayan dari PPP Tegalsari menggunakan kapal berukuran 6 GT (Tabel 1). Namun nelayan dari Desa Tabanio Kabupaten Tanah Laut Provinsi Kalimantan Selatan mengoperasikan alat tangkap ini menggunakan kapal berukuran sedikit lebih besar, yakni 7-10 GT (Aminah 2015). Sedangkan, alat tangkap mini purse seine dioperasikan oleh nelayan dari PPP Tegalsari menggunakan kapal berukuran 9 GT. Berdasarkan hasil penelitian Restumurni, Bambang dan Dewi (2016), alat tangkap mini purse seine juga dioperasikan oleh nelayan dari Demak menggunakan kapal berukuran 9 GT.

\section{Lama untuk Satu Kali Operasi Penang- kapan Ikan}

Waktu yang dibutuhkan untuk satu kali operasi penangkapan ikan atau waktu mulai dari menebar jaring hingga menariknya kembali ke atas kapal dapat berbeda-beda, tergantung dari jenis alat tangkap yang digunakan. Berdasarkan hasil wawancara dengan responden, penerapan lama waktu mulai jaring ditebar hingga ditarik kembali dapat menentukan jumlah hasil tangkapan ikan yang diperoleh. Gambar 1 menunjukkan rata-rata waktu yang dibutuhkan untuk setiap kali operasi penangkapan ikan pada masing-masing jenis alat tangkap.

Gambar 1 menunjukkan waktu yang paling lama untuk satu kali operasi penangkapan ikan terdapat pada pengoperasian alat tangkap gillnet (3 jam), diikuti oleh arad (2,93 jam). Sedangkan waktu yang paling singkat 
Tabel 1 Alat tangkap berdasarkan GT kapal

\begin{tabular}{ll}
\hline \multicolumn{1}{c}{ Alat Tangkap } & \multicolumn{1}{c}{ Ukuran Kapal (GT) } \\
\hline Cantrang & 5,6 , dan 10 \\
Arad & $3,5,6$, dan 10 \\
Gillnet & 6 \\
Mini purse seine & 9 \\
\hline
\end{tabular}

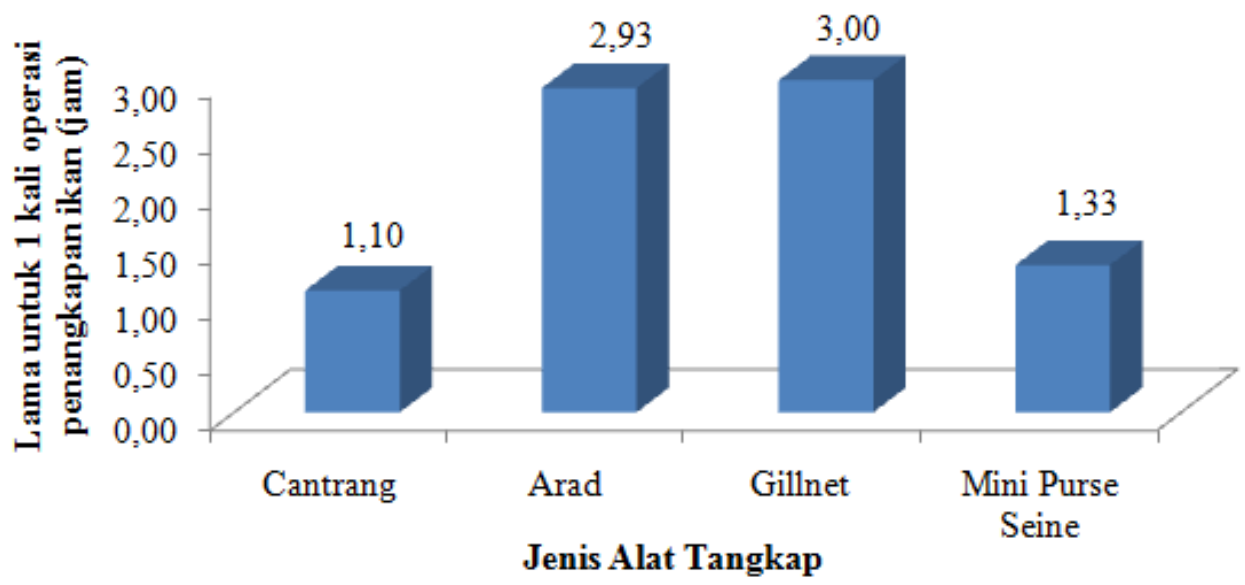

Gambar 1 Lama untuk satu kali operasi penangkapan ikan

untuk satu kali operasi penangkapan ikan terdapat pada pengoperasian alat tangkap cantrang $(1,10$ jam) dan mini purse seine $(1,33$ jam). Apabila waktu operasi penangkapan ikan per trip antar alat tangkap sama, maka cantrang dan mini purse seine cenderung dapat dioperasikan lebih sering dibandingkan arad dan gillnet. Perbedaan cara pengoperasian ini dapat menunjukkan efektivitas konsumsi waktu dari keempat alat tangkap dalam melakukan penangkapan.

Lama waktu satu kali operasi penangkapan ikan pada alat tangkap gillnet yang dioperasikan nelayan PPP Tegalsari ternyata memiliki kesamaan dengan yang dilakukan nelayan Brebes. Soaking time jaring gillnet terbaik nelayan Brebes adalah selama 3 jam. Lama waktu ini yang membuat nelayan Brebes mendapatkan jumlah dan bobot hasil tangkapan berupa ikan kembung yang paling banyak (Mardiansyah 2015).

Alat tangkap cantrang dioperasikan melalui beberapa tahapan, yakni: tahap persiapan, tahap setting (menebar), tahap towing (menarik) dan tahap hauling (mengangkat jaring). Proses setting yang dilakukan nelayan dari Tuban memerlukan waktu sekitar 10-15 menit dan proses towing memerlukan waktu sekitar $25-40$ menit (Aji et al. 2013). Lama waktu mulai dari proses setting hingga towing yang dilakukan nelayan dari Rembang dalam pengoperasian cantrang membutuhkan waktu sekitar 65 menit (Bayyinah et al. 2014). Lama penarikan alat tangkap cantrang selama 60 menit yang dilakukan nelayan dari Brondong mendapatkan hasil tangkapan lebih baik dengan jumlah ikan yang diperoleh lebih banyak (Suwarsih 2013). Sejalan dengan hal ini, nelayan dari PPP Tegalsari secara rata-rata juga melakukan pengoperasian alat tangkap cantrang selama 1,1 jam.

Alat tangkap arad dioperasikan melalui tiga tahapan yaitu: tahap setting, tahap dragging, dan tahap hauling. Lama setting hingga hauling yang dilakukan nelayan dari Kendal adalah 120-150 menit atau 2-2,5 jam (Widyawati et al. 2014). Lama waktu pengoperasian arad yang dilakukan nelayan dari PPP Tegalsari mulai dari setting hingga hauling adalah 2,9 jam, sedikit agak lebih lama dibanding lama waktu pengoperasian arad yang diterapkan nelayan dari Kendal.

Pengoperasian alat tangkap mini purse seine dilakukan melalui empat tahapan, yakni: tahap penurunan lampu, tahap setting (penurunan jaring), tahap hauling (penarikan jaring) dan tahap pengumpulan hasil tangkapan (Pujianto et al. 2013). Nelayan dari Probolinggo menerapkan lama setting dari alat tangkap ini sekitar 5 menit dan waktu yang dibutuhkan jaring untuk tenggelam hingga membentuk dinding silinder adalah 561 detik atau 9,35 menit (Muntaha et al. 2013). Nelayan dari Pekalongan menerapkan lama setting 2,71 menit dan lama hauling 11,55 menit dalam pengoperasian alat tangkap mini purse seine (Maulana et al. 2017). 


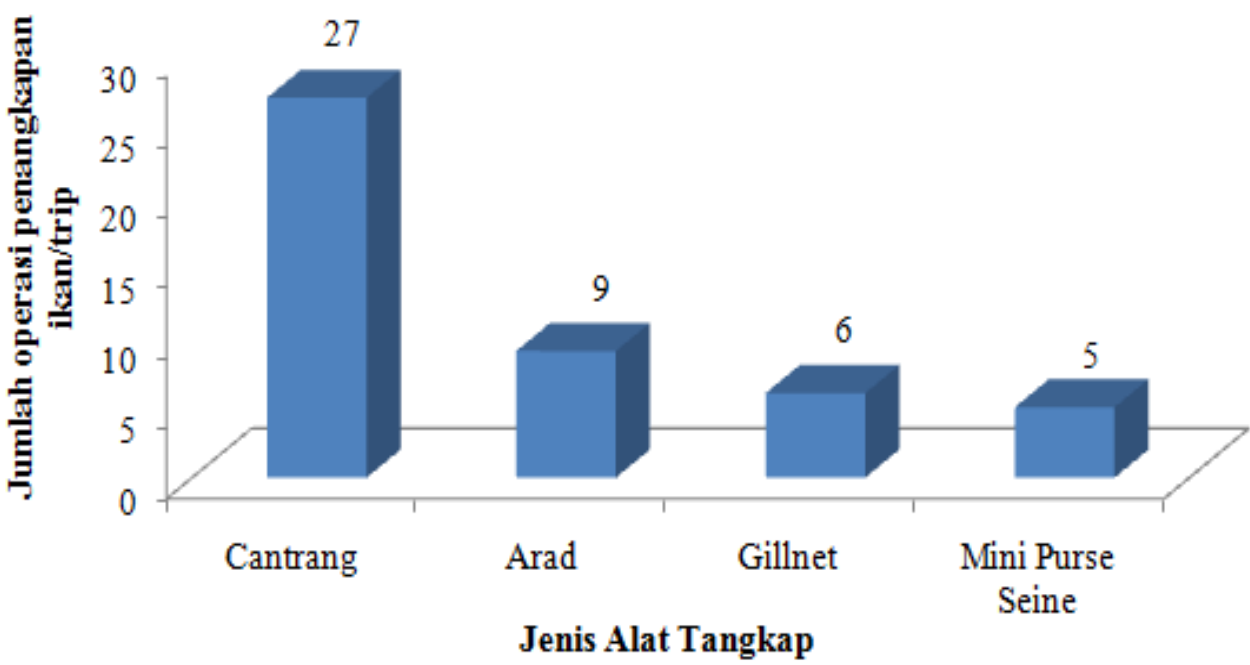

Gambar 2 Rata-rata jumlah operasi penangkapan ikan per trip dari masing-masing jenis alat tangkap

Nelayan dari PPP Tegalsari menerapkan lama waktu untuk 1 kali operasi penangkapan ikan menggunakan alat tangkap mini purse seine, mulai dari tahap persiapan, tahap setting, tahap hauling hingga tahap pengumpulan hasil tangkapan adalah 79,8 menit atau 1,33 jam.

\section{Jumlah Operasi Penangkapan Ikan per Trip}

Jumlah operasi penangkapan ikan dapat diartikan sebagai jumlah aktivitas penangkapan ikan sejak alat tangkap mulai ditebar ke perairan hingga ditarik kembali ke atas kapal. Apabila cuaca mendukung dan stok sumber daya ikan stabil, maka jumlah operasi penangkapan ikan per trip akan berbanding lurus dengan produktivitas penangkapan ikan (Aji et al. 2013). Berikut adalah rata-rata jumlah operasi penangkapan ikan per trip berdasarkan jenis alat penangkapan ikan yang digunakan nelayan dari PPP Tegalsari.

Gambar 2 menunjukkan bahwa jumlah operasi penangkapan ikan per trip yang diterapkan pada masing-masing jenis alat tangkap cukup beragam. Alat tangkap yang dioperasikan dengan frekuensi paling tinggi adalah cantrang (27 kali/trip), lalu diikuti oleh alat tangkap arad (9 kali/trip), baru kemudian gillnet (6 kali/ trip). Adapun alat tangkap yang dioperasikan dengan frekuensi paling rendah adalah mini purse seine yakni hanya 5 kali/trip.

Cantrang dan arad dapat dioperasikan dengan frekuensi lebih tinggi dibanding gillnet dan mini purse seine karena cantrang dan arad pengoperasiannya cukup sederhana, yakni hanya dengan cara menebar jaring ke perairan kemudian menariknya kembali (BPPI 1999 dalam Suwarsih 2013; Indrawasih dan Wahyo- no 2009). Selain itu karena alat bantu yang digunakan dalam pengoperasian kedua alat tangkap ini lebih simpel yakni gardan (Riyanto et al. 2011; Manadiyanto et al. 2000).

Alat tangkap gillnet dioperasikan dengan cara meletakkan jaring menghadang arus (Lanes et al. 2013). Melalui cara ini, nelayan berharap ada ikan yang terbawa arus dan kemudian terjerat pada jaring. Jika lama perendaman jaring gillnet makin lama, diharapkan nelayan akan mendapatkan hasil tangkapan yang lebih banyak. Nelayan dari PPP Tegalsari menerapkan lama untuk satu kali operasi penangkapan ikan menggunakan alat tangkap gillnet dalam waktu sekitar 3 jam (Gambar 1). Durasi ini paling lama dibanding pengoperasian alat tangkap jenis lainnya, ditambah lagi ukuran kapal dari armada gillnet hanya 6 GT (Tabel 1), menyebabkan jumlah operasi penangkapan ikan per tripnya menjadi sedikit yakni hanya 6 kali.

Alat tangkap mini purse seine dioperasikan dengan menggunakan alat bantu yang beragam, yakni: gardan, lampu cumi, lampu galaksi, lampu ancak, dan rumpon waring (Tanjov 2016). Mini purse seine dioperasikan dengan menerapkan empat tahap kegiatan. Pertama, peletakkan rumpon di daerah penangkapan yang telah ditentukan, dilanjutkan dengan penyalaan lampu cumi, lampu galaksi dan lampu ancak secara berurutan. Lalu pelingkaran jaring pada daerah penangkapan bersamaan dengan penyalaan lampu ancak, dan terakhir penarikan tali cincin dan penarikan hasil tangkapan ke atas kapal (Erfan 2008). Cara pengoperasiannya cukup rumit, ditambah lagi alat tangkap ini termasuk alat tangkap pasif yang menunggu ikan mendatangi alat tangkap ini. Hal ini yang diduga menyebabkan jumlah operasi penangkapan ikan menggunakan alat tangkap mini 
purse seine menjadi yang paling sedikit yakni hanya 5 kali/trip.

Jika ditinjau dari ukuran kapal yang digunakan saat operasi penangkapan ikan menunjukkan pada pengoperasian alat tangkap cantrang maupun arad memperlihatkan pola yang sama yakni makin besar ukuran kapal, makin banyak pula jumlah operasi penangkapan ikan yang dapat dilakukan untuk setiap trip (Gambar 3). Hal ini menunjukkan penggunaan kapal pada ukuran yang lebih besar dapat memberikan peluang untuk melakukan operasi penangkapan ikan dengan frekuensi yang lebih tinggi. Frekuensi operasi penangkapan ikan per trip tertinggi terdapat pada pengoperasian alat tangkap yang menggunakan kapal berukuran 10 GT, yakni 64 kali/trip untuk cantrang dan 19 kali/trip untuk arad.

\section{Produktivitas Alat Tangkap}

Produktivitas alat tangkap merupakan ukuran kemampuan suatu alat penangkapan ikan dalam mendapatkan hasil tangkapan yang menghubungkan antara variabel hasil tangkapan dengan effort penangkapan (Wiyono 2010). Pada penelitian ini, effort adalah jumlah trip.
Rata-rata produktivitas dari masing-masing jenis alat tangkap seperti yang disajikan pada Gambar 4.

Gambar 4 menunjukkan produktivitas tertinggi terdapat pada armada penangkapan ikan yang menggunakan alat tangkap cantrang (5163 kg/trip). Hal ini diduga disebabkan alat tangkap tersebut: 1) mudah dioperasikan yakni hanya dengan menebar jaring dan menariknya kembali, 2) cara kerjanya melalui proses penyapuan terhadap sumber daya perikanan yang dilaluinya (Badan Standarisasi Nasional, 2006), dan 3) waktu yang dibutuhkan untuk setiap operasi penangkapan ikan relatif singkat yakni 1,1 jam (Gambar 1) sehingga operasi penangkapan ikan dapat dilakukan dengan frekuensi yang tinggi dalam 1 tripnya, yakni 27 kali/trip (Gambar 2).

Alat tangkap arad dioperasikan dengan cara yang sama dengan cantrang, hanya saja pada saat penarikan dan pengangkatan jaring arad ke atas kapal dilakukan dalam keadaan kapal berjalan secara perlahan. Sedangkan cantrang diangkat dan ditarik ke atas kapal dalam keadaan kapal diam (Salim dan Suwardi 2013). Oleh karena jumlah operasi penangkap-

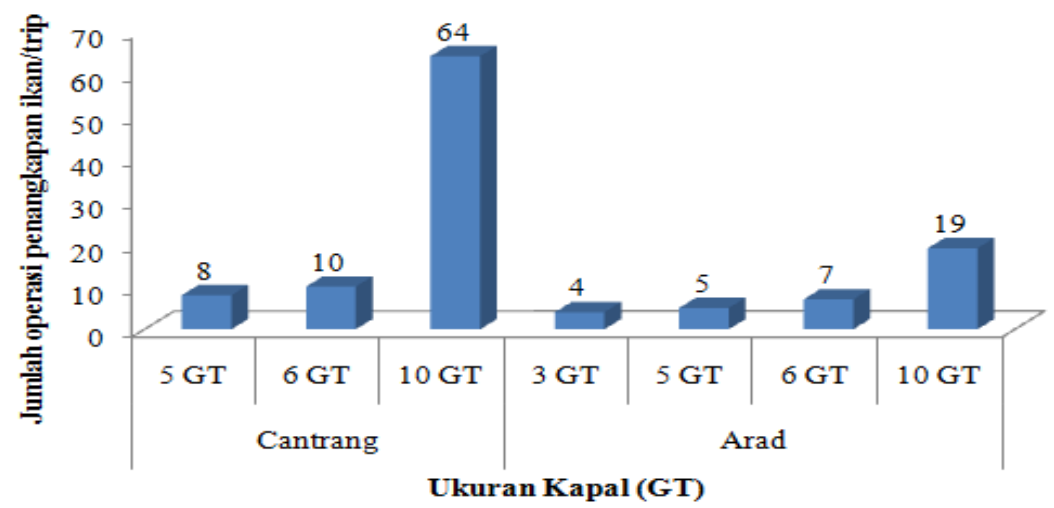

Gambar 3 Jumlah operasi penangkapan ikan per trip dari alat tangkap cantrang dan arad berdasarkan GT kapal

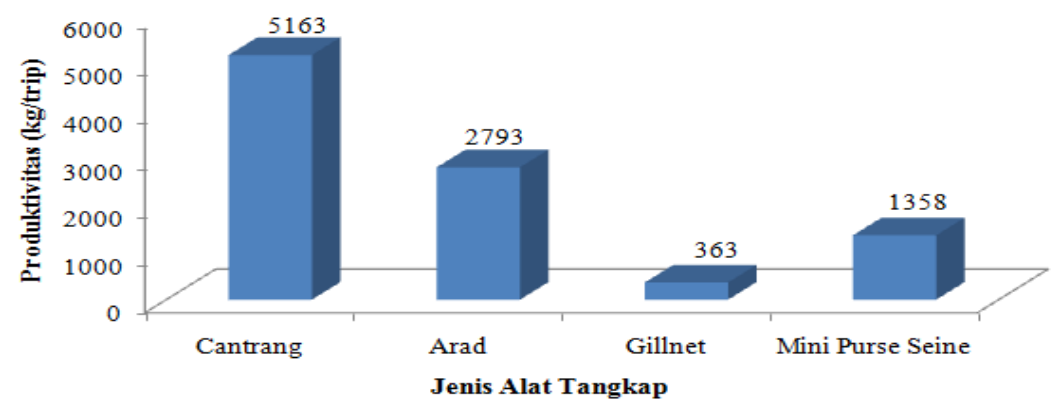

Gambar 4 Rata-rata produktivitas dari masing-masing jenis alat tangkap an ikan menggunakan alat tangkap arad hanya 9 kali, sementara jumlah operasi penangkapan ikan menggunakan alat tangkap cantrang adalah 27 kali, menyebabkan produktivitas arad menjadi lebih rendah dibanding cantrang (Gambar 4). 
Alat tangkap gillnet merupakan alat tangkap yang memiliki produktivitas terendah (Gambar 4). Hal ini disebabkan pada perikanan skala kecil (< $10 \mathrm{GT}$ ), alat tangkap ini hanya dioperasikan dengan menggunakan kapal berukuran 6 GT (Tabel 1). Oleh karena itu, perbekalan yang mampu dibawa untuk keperluan selama melaut maupun ukuran palka yang dapat digunakan untuk menyimpan hasil tangkapan menjadi relatif kecil (Fitriyashari et al. 2014). Hal ini menyebabkan kegiatan penangkapan ikan menjadi relatif terbatas baik daerah penangkapan yang dapat dijangkau maupun waktu operasi penangkapan per trip menjadi lebih singkat dibanding kegiatan penangkapan ikan dengan menggunakan kapal yang lebih besar. Selain itu, gillnet merupakan alat tangkap pasif yang menunggu ikan terjerat pada jaring dengan lama untuk satu kali operasi penangkapan selama 3 jam. Durasi ini merupakan waktu yang paling lama dibandingkan dengan pengoperasian cantrang, arad dan mini purse seine. Kondisi ini menyebabkan frekuensi dan produktivitas operasi penangkapan menggunakan gillnet menjadi rendah.

Sementara itu, pada alat tangkap mini purse seine, meskipun dioperasikan menggunakan kapal berukuran 9 GT (Tabel 1), namun karena rata-rata jumlah operasi penangkapan ikan hanya 5 kali/trip (Gambar 2) menyebabkan produktivitas dari alat tangkap mini purse seine menjadi lebih rendah dibandingkan produktivitas armada cantrang dan arad (Gambar 4).

\section{Kompetisi antar Alat Tangkap}

Dua atau lebih jenis alat tangkap yang berbeda dapat saja memiliki produktivitas yang sama atau memiliki kecenderungan mendapatkan jenis ikan yang hampir sama dengan bobot yang hampir sama pula. Apabila hal ini terjadi, maka dapat dikatakan antar alat tangkap tersebut saling berkompetisi dalam mendapatkan hasil tangkapan.

Kompetisi antar alat tangkap dalam mendapatkan hasil tangkapan dapat terjadi sebagai akibat tempat operasi (fishing ground) yang sama (Boncoeur et al. 1998) dalam memperebutkan sumber daya ikan yang sama (Ulrich et al. 2001), ada kesesuaian kedalaman dalam pengoperasian alat tangkap dengan swimming layer ikan (Pranata 2013), dan keefektifan antar alat tangkap yang hampir sama dalam mendapatkan hasil tangkapan (Wiyono et al. 2006). Kompetisi antar alat tangkap perlu mendapat perhatian karena dapat berpengaruh terhadap ketersediaan stok ikan tertentu, khususnya apabila ada keterbatasan sumber daya ikan di daerah penangkapan dan jumlah dari jenis ikan tertentu yang tertangkap melebihi dari batas yang dapat ditoleransikan.

Informasi tentang alat tangkap yang saling berkompetisi secara ketat dapat dijadikan alternatif untuk dapat saling menggantikan dalam penggunaannya. Khususnya antara alat tangkap yang tidak ramah lingkungan dengan

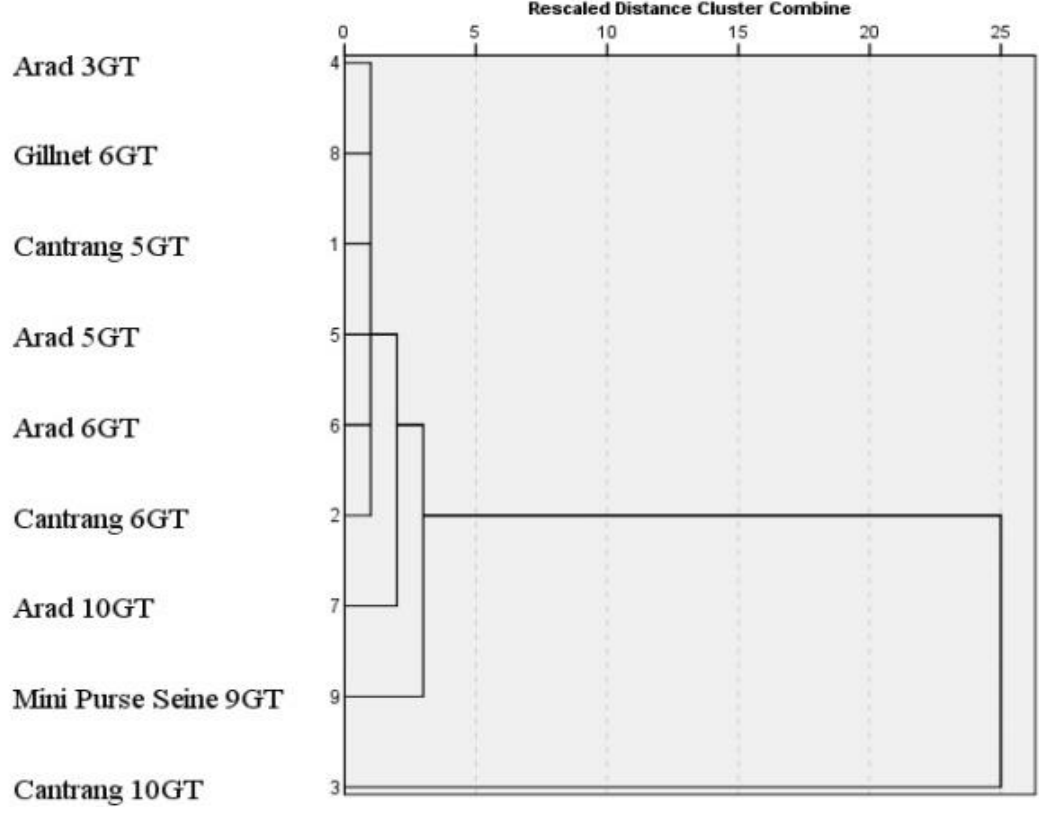

Gambar 5 Kompetisi antar alat tangkap

alat tangkap yang ramah lingkungan atau antara alat tangkap yang sama-sama ramah lingkungan tetapi berbeda dalam hal kemudahan pengoperasiannya, namun antara alat tangkap ini memperoleh hasil tangkapan dengan jenis dan bobot yang hampir sama. Implikasinya 
bahwa dari alat tangkap yang saling berkompetisi dapat dipilih alat tangkap yang sebaiknya digunakan nelayan.

Informasi tentang kompetisi antar alat tangkap dapat juga dijadikan acuan bagi pengambil kebijakan dalam pemberian arahan pada nelayan yang menggunakan alat tangkap tidak ramah lingkungan agar beralih menggunakan alat tangkap ramah lingkungan. Selain itu, informasi tentang kompetisi antar alat tangkap juga dapat dijadikan acuan dalam membatasi penggunaan alat tangkap yang saling berkompetisi untuk menjaga stok sumber daya ikan tertentu, dan dapat dijadikan alternatif bagi nelayan untuk memilih alat tangkap yang lebih praktis pengoperasiannya.

Berdasarkan hasil olah data pada hasil tangkapan ikan yang diperoleh nelayan PPP Tegalsari, ternyata terjadi kompetisi antar alat tangkap yang digunakan. Pada Gambar 5 disajikan dendogram pengelompokkan alat tangkap berdasarkan kesamaan hasil tangkapan yang menunjukkan terjadi kompetisi antar alat tangkap tersebut.

Gambar 5 menunjukkan bahwa berdasarkan GT kapal yang digunakan saat operasi penangkapan ikan, alat tangkap yang saling berkompetisi secara ketat dalam mendapatkan hasil tangkapan adalah: cantrang 5 GT, cantrang $6 \mathrm{GT}$, arad $3 \mathrm{GT}$, arad $5 \mathrm{GT}$, arad $6 \mathrm{GT}$, dan gillnet $6 \mathrm{GT}$. Hal ini ditunjukkan oleh jarak ke arah kanan yang sangat dekat. Jarak ini menunjukkan ketidaksamaan hasil tangkapan baik jenis dan bobotnya. Kompetisi secara ketat di antara alat tangkap tersebut dapat terjadi karena ukuran kapal yang relatif sama, yakni antara 3-6 GT, sehingga diduga ada kesamaan daerah penangkapan ikan untuk alat tangkap tersebut. Berdasarkan informasi yang diperoleh dari nelayan, ternyata kegiatan penangkapan ikan hanya dilakukan di Perairan Tegal atau Wilayah Pengelolaan Perikanan Republik Indonesia 712 dan jalur 1 (2-4 mil dari garis pantai). Hal ini sebagai akibat keterbatasan perbekalan dan ukuran palka. Oleh karenanya, pada hasil tangkapannya memiliki kesamaan baik jenis maupun bobotnya. Di sisi lain, pada alat tangkap yang dioperasikan dengan kapal berukuran yang lebih besar seperti halnya mini purse seine yang dioperasikan menggunakan kapal berukuran 9 GT, dan arad yang dioperasikan menggunakan kapal berukuran 10 GT berada pada tingkatan kompetisi yang lebih rendah. Bahkan pada alat tangkap cantrang yang dioperasikan dengan menggunakan kapal berukuran 10 GT ternyata memiliki tingkatan kompetisi yang sangat rendah, bahkan dapat dikatakan tidak saling berkompetisi pada suatu klaster dengan alat tangkap lainnya (ditunjukkan oleh ni- lai ketidaksamaan yang sangat besar) (Gambar 5). Hal ini disebabkan alat tangkap cantrang yang menggunakan kapal berukuran 10 GT dioperasikan dengan jumlah operasi penangkapan ikan per trip yang paling tinggi yakni 64 kali (Gambar 3). Artinya, alat tangkap ini dapat dioperasikan berkali-kali sehingga mendapatkan jumlah hasil tangkapan yang jauh lebih tinggi (Gambar 4).

\section{KESIMPULAN}

Ukuran kapal yang digunakan dalam operasi penangkapan ikan dari masing-masing jenis alat tangkap adalah cantrang $(5,6,10$ GT), arad (3,5,6,10 GT), gillnet (6 GT) dan mini purse seine (9 GT). Waktu yang dibutuhkan untuk satu kali operasi penangkapan ikan dari masing-masing alat tangkap adalah cantang 1,10 jam, arad 2,93 jam, gillnet 3,00 jam dan mini purse seine 1,33 jam. Jumlah operasi penangkapan ikan per trip dari masing-masing jenis alat tangkap adalah cantrang $27 \mathrm{kali}$, arad 9 kali, gillnet 6 kali dan mini purse seine 5 kali. Produktivitas dari masing-masing alat tangkap adalah cantrang $5163 \mathrm{~kg} /$ trip, arad $2793 \mathrm{~kg} /$ trip, gillnet $363 \mathrm{~kg} /$ trip dan mini purse seine 1358 $\mathrm{kg} /$ trip. Alat tangkap yang saling berkompetisi secara ketat adalah cantrang (5 dan 6 GT), arad $(3,5$ dan $6 \mathrm{GT})$, dan gillnet 6 GT. Alat tangkap yang tidak berkompetisi dengan alat tangkap lainnya adalah cantrang yang dioperasikan menggunakan kapal 10 GT.

\section{SARAN}

Perlu dilakukan penelitian lanjutan tentang jenis ikan hasil tangkapan yang diperoleh dari alat tangkap yang saling berkompetisi untuk mengetahui jenis ikan yang terekploitasi.

\section{UCAPAN TERIMA KASIH}

Penulis mengucapkan terima kasih kepada Bapak H. Tasman selaku Ketua Himpunan Nelayan di PPP Tegalsari dan para nelayan yang menjadi responden karena telah membantu pelaksanaan penelitian ini. Penulis juga mengucapkan terima kasih kepada para Reviewer serta semua pihak yang telah membantu terwujudnya tulisan ini.

\section{DAFTAR PUSTAKA}

Aji IN, Wibowo BA, Asriyanto. 2013. Analisis Faktor Produksi Hasil Tangkapan Alat Tangkap Cantrang di Pangkalan Pendaratan Ikan Bulu Kabupaten Tuban. Jour- 
nal of Fisheries Resources Utilization Management and Technology. 2(4): 5058.

Aminah S. 2015. Manajemen Operasi Penangkapan Gillnet Millenium di Desa Tabanio Kabupaten Tanah Laut. Journal Fish Scientiae. 5(10): 110-121.

Atmaja SB, Nugroho. 2012. Distribusi Spasial Upaya Penangkapan Kapal Cantrang dan Permasalahannya di Laut Jawa. Jurnal Penelitian Perikanan Indonesia. 18 (4): 233-241.

Atmaja SB, Sadhotomo B. 2012. Kompetisi dan Interaksi Perikanan: Studi kasus pada Perikanan Layang (Decapterus spp.) di Laut Jawa. Jurnal Penelitian Perikanan Indonesia. 18(3): 197-204.

Badan Standarisasi Nasional. 2006. Standar Nasional Indonesia (SNI). SNI 01-72362006. Bentuk Baku Konstruksi Pukat Tarik Cantrang. Jakarta: Dewan Standarisasi Indonesia.

Bayyinah AA, Ismail, Hapsari TD. 2014. Analisis Finansial Usaha Perikanan Tangkap Cantrang 30 GT di Pelabuhan Perikanan Pantai (PPP) Tasik Agung Rembang. Journal of Fisheries Resources Utilization Management and Technology. 3(3): 218227.

Boncoeur J, Berthou P, Prat JL, Latrouite D, Le Gallic B, Fifas S, Curtil O. 1998. Fisheries Conflicts and Fisheries Management in the Normand-Breton Gulf (ICES VIle). Xth Annual Conference of the EAFE (European Association of Fisheries Economists), The Hague. Netherlands (NL). April 1-4 1998.

Cahyani RT. 2013. Kajian Penggunaan Cantrang terhadap Kelestarian Sumber daya Ikan Demersal (Analisis Hasil Tangkapan Dominan yang Didaratkan di TPI Wedung Demak). [Tesis]. Semarang: Universitas Dipenogoro.

Erfan ER. 2008. Analisis Kegiatan Operasi Kapal Purse Seine yang Berbasis di Pelabuhan Perikanan Nusantara (PPN) Pekalongan. [Skripsi]: Bogor: Institut Pertanian Bogor.

Fitriyashari A, Rosyid A, Ayunita D. 2014. Analisis Kebutuhan Perbekalan Kapal Penangkap Ikan di Pelabuhan Perikanan Pantai Tasikagung, Rembang. Journal of Fisheries Resources Utilization Management and Technology. 3(3): 112-130.
Indrawasih R, Wahyono A. 2009. Pengoperasian Jaring Arad di Perairan Pantai Utara Jawa: Masalah dan Penyelesaiannya. Jurnal Kebijakan dan Riset Sosial Ekonomi Kelautan dan Perikanan. 4(1): 81-91

Junus N. 2012. Sistem Hukum Pengelolaan Wilayah Pesisir dan Laut menurut UndangUndang Pemerintah Daerah. Jurnal INOVASI. 9(2): 1-9.

Khaerudin A. 2006. Proporsi Hasil Tangkap Sampingan Jaring Arad (Mini Traw) yang Berbasis di Pesisir Utara, Kota Cirebon. [Skripsi]. Bogor: Institut Pertanian Bogor.

Lanes S, Pontoh O, Lumenta V. 2013. Manajemen Usaha Perikanan Jaring Insang Dasar di Kelurahan Manado Tua 1 Kota Manado. AKULTURASI. 1(1): 21-25.

Mahardikha M. 2008. Pengaruh Jenis Alat Tangkap terhadap Tingkat Kesejahteraan Nelayan di Kelurahan Tegalsari dan Muarareja, Tegal, Jawa Tengah [Skripsi]. Bogor: Institut Pertanian Bogor.

Manadiyanto $H$, Latif $H$, Iriandi S. 2000. Status Penangkapan Udang Penaeid Pasca Pukat Harimau di Perairan Laut Jawa. Jakarta: Balai Penelitian Perikanan Laut. 26 hal.

Mardiansyah, Asriyanto, Setiyanto I. 2015. Analisis Perbedaan Lama Perendaman dan Waktu Penangkapan pada Jaring Koncong (Encircling Gillnet) terhadap Hasil Tangkapan Ikan Kembung (Rastrelliger Sp.) di Desa Pulolampes, Brebes. Journal of Fisheries Resources Utilization Management and Technology. 4(4): 5766.

Maulana RA, Sardiyatmo, Kurohman F. 2017. Pengaruh Lama Waktu Setting dan Penarikan Tali Kerut (Purse Line) terhadap Hasil Tangkapan Alat Tangkap Mini Purse Seine di Pelabuhan Perikanan Nusantara Pekalongan. Journal of Fisheries Resources Utilization Management and Technology. 6(4): 11-19.

Muntaha S, Soemarno, Muhammad S, Wahyudi S. 2013. Kajian Kecepatan Kapal Purse Seiner terhadap Hasil Tangkapan Ikan di Perairan Probolinggo. Jurnal Kelautan. 6(1): 1-7.

Pan M, Walden J. 2015. Measuring Productivity in a Shared Stock Fishery: A Case Study of the Hawaii Longline Fishery. Journal Marine Policy. 62: 302-308.

Pranata SA. 2013. Kedalaman Lapisan Renang Tuna (Thunnus Sp.) yang tertangkap 
oleh Rawai Tuna di Samudera Hindia. [Skripsi]. Bogor: Institut Pertanian Bogor.

Pujianto, Boewono H, Wijayanto D. 2013. Analisis Kelayakan Usaha Aspek Finansial Penangkapan Mini Purse Seine dengan Ukuran Jaring yang Berbeda di PPI Ujungbatu Kabupaten Jepara. Journal of Fisheries Resources Utilization Management and Technology. 2(2): 124-133.

Restumurni D, Bambang AN, Dewi DANN. 2016. Analisis Pendapatan Nelayan Alat Tangkap Mini Purse Seine 9 GT dan 16 GT di Pelabuhan Perikanan Pantai (PPP) Morodemak, Demak. Journal of Fisheries Resources Utilization Management and Technology. 5(1): 78-86.

Riyanto M, Purbayanto A, Mawardi W, Suheri N. 2011. Kajian Teknis Pengoperasian Cantrang di Perairan Brondong, Kabupaten Lamongan, Jawa Timur. Buletin PSP. XIX((1): 97-104.

Salim A, Suwardi. 2013. Pengoperasian Jaring Cantrang dalam Uji Coba Mata Jaring Bujur Sangkar (square mesh panel) pada Kantong. BTL. 11(1): 61-70.

Setianto I. 2007. Kapal Perikanan. Semarang: Universitas Diponegoro.

Sulistyowati. 2017. Analisis Tingkat Efisiensi Penangkapan dengan Jaring Arad di Kabupaten Batang. Jurnal Dinamika Sosial Ekonomi. 6(1): 1-14.

Susanto B, Anna Z, Gummilar I. 2015. Analisis Bioekonomi dan Pengelolaan Sumber Daya Ikan Mas (Cyprinus carpio) di Waduk Cirata Jawa Barat. Jurnal Perikanan dan Kelautan. 4(2): 32-42.

Suwarsih. 2013. Pengaruh Lama Penarikan pada Pengoperasian Alat Tangkap Cantrang terhadap Hasil Tangkapan Ikan Demersal di Perairan Brondong. Jurnal Harpodon Borneo. 6(2): 143-151.
Tanjov YE. 2016. Pemanfaatan Sumber Daya Ikan Menggunakan Mini Purse Seine di PPP Lempasing, Provinsi Lampung. [Tesis]. Bogor: Institut Pertanian Bogor.

Ulrich C, Gascuel D, Dunn MR, Gallic LB, Dintheer C. 2001. Estimation of Technical Interaction due to the Competition for Resource in A Mixed Species Fishery, and the Typology of Fleets and Métiers in the English Channel. Aquat. Living Resourcesi. 14(5): 267-281.

Widyawati A, Fitri ADP, Hapsari TD. 2014. Analisis Teknis dan Ekonomi Alat Tangkap Arad (Genuine Small Trawl) dan Arad Modifikasi (Modified Small Trawl) di PPP Tawang Kendal. Journal of Fisheries Resources Utilization Management and Technology. 3(3): 228-237.

Wiyono ES, Yamada S, Tanaka E, Arimoto T, Kitakado T. 2006. Dynamics of Fishing Gear Allocation by Fishers in SmallScale Coastal Fisheriess of Palabuhanratu Bay, Indonesia. Fisheries Research Journal. Tokyo (JP): Blackwell Publishing Ltd.

Wiyono ES. 2010. Komposisi, Diversitas dan Produktivitas Sumber Daya Ikan Dasar di Perairan Pantai Cirebon, Jawa Barat. Jurnal IImu Kelautan. 15(4): 214-220.

Wurlianty HA, Wenno J, Kayadoe ME. 2015. Catch Per Unit Effort (CPUE) Periode Lima Tahunan Perikanan Pukat Cincin di Kota Manado dan Kota Bitung. Jurnal IImu dan Teknologi Perikanan Tangkap. 2(1): 1-8.

Yulianto S, Hidayatullah KH. 2014. Analisis Klaster untuk Pengelompokan Kabupaten/Kota di Provinsi Jawa Tengah Berdasarkan Indikator Kesejahteraan Rakyat. Jurnal Statistika. 2(1): 56-63. 